\title{
Essential Platform Infrastructure and the Need for Regulation
}

\author{
Sebastian Hermes \\ Technical University of Munich \\ sebastian.hermes@tum.de
}

\author{
Maximilian Schreieck \\ Technical University of Munich \\ maximilian.schreieck@tum.de
}

\author{
Jason Bennett Thatcher \\ Temple University \\ jason.thatcher@temple.edu
}

\begin{abstract}
Digital platforms have become a ubiquitous phenomenon and sparked innovation in various industries. However, digital platforms have also raised concerns about competition, privacy, labor protection, democracy, and negative externalities. This is why platform regulation has gained significant attention from research and practice in recent years. Regulators face the challenge of predicting the importance of a new platform of investigation with limited resources and a growing platform economy. To address this challenge, we develop a framework building on infrastructural properties, platform properties, and the notion of essentiality. We derive the concept of essential platform infrastructure to determine the need for regulation. We propose that the degree of essentiality of a digital platform and its appropriation of infrastructural properties are two dimensions indicating the magnitude of potential damage that a platform can cause in case it abuses its power, thereby indicating an increased need for regulation.
\end{abstract}

\section{Introduction}

Digital platforms have become ubiquitous and prevail in various industries ranging from operating systems, e-commerce, and social media to the sharing economy, search engines, payment, booking, and many more [1]. Digital platforms have created an enormous economic surplus for consumers and businesses. Nonetheless, digital platforms have also raised concerns about competition, privacy, labor protection, democracy, and negative externalities [27]. Although they have largely avoided regulation in the past, digital platforms have been increasingly scrutinized and penalized by regulators in the last years. For example, Google has been penalized for tying its comparison shopping service to its dominant search engine and demoting rivals in search results [8] as well as for abusing its Mobile Applications Distribution Agreement for enveloping mobile search and mobile browsers [9].
Against the backdrop of a significantly growing platform economy, limited regulatory resources (e.g., number of employees in general and technology experts in particular [10]), and increasing abuses of power, regulators need guidance to determine which platforms should be regulated and which they can leave out of consideration. This struggle is currently reflected in the EU Commission's effort to develop the Digital Markets Act, in which it aims to define large, systemic online platforms to impose specific obligations on those "gatekeepers" [11].

Establishing, if not predicting, the importance of a new platform of investigation is a critical task for researchers and regulators [12]. To this end, we develop a framework comprising infrastructural properties, platform properties, and the notion of essentiality. Moreover, we propose the concept of essential platform infrastructure to derive the need for regulation. Our framework differentiates four types of platforms: (1) basic platforms, (2) essential platforms, (3) infrastructuralized platforms, and (4) essential, infrastructuralized platforms. The fourth type is what we term, for simplicity reasons, essential platform infrastructure and it represents digital platforms that are large in scale and scope (infrastructuralized), and perceived to compete against no viable alternative (essential). We discuss that the degree of essentiality of a digital platform and its appropriation of infrastructural properties are two dimensions indicating the magnitude of potential damage that a platform can cause in case it abuses its power. Hence, the more essential a digital platform becomes to users and the more it expands its scale and scope, the higher the need for regulation.

The remainder of the paper is structured as follows. Section 2 introduces the properties of infrastructures and digital platforms, reviews the notion of essentiality, and outlines the concepts of abuse of power and regulation. Section 3 theorizes the intersections of infrastructures, platforms, and essentiality to derive a framework for essential platform infrastructure. Section 4 discusses how the essentiality of a digital platform and its infrastructural properties can be employed to derive the need for regulation. Section 5 outlines the theoretical and practical implications of essential platform 
infrastructure. Section 6 presents avenues for future research. Finally, Section 7 concludes the paper.

\section{Theoretical Primer}

\subsection{Properties of Infrastructures}

Common metaphors present infrastructures as supporting layers or substructures, referring to the concept that infrastructures are a foundation on which something else runs or operates. In this sense, earlier infrastructures of the 19th century include roads, canals, water systems, railroads, and electric grids, whereas digital infrastructures of the late 20th and early 21 st centuries comprise examples such as the Internet, data centers, and open standards (e.g., XML or TCP) [13-15]. Following Star and Ruhleder [16], we argue that such metaphors are not accurate. They assume that some things are per se infrastructures, whereas others are not. Opposing this view, we argue that infrastructure is a relational concept [17]. That is, things become infrastructure in relation to practice and are not a priori infrastructure. In other words, nothing is per se infrastructure, but everything can become infrastructure when it adopts infrastructural properties.

The perspective of when - not what-is an infrastructure is also in line with recent work on digital infrastructures as Constantinides, et al. [13] noted that "smartphones are powerful computational and networking devices serving as infrastructures once they scale to a critical mass" (italic added by the authors). With the relational concept in mind, infrastructures, independent of whether they transfer physical or digital material, emerge to have the following properties:

1. Embeddedness: Infrastructure is composed of and sunk into other structures, arrangements, capabilities, and technologies $[14,16]$.

2. Recursively organized: Infrastructure shapes and is shaped by a community of practice; it is both an outcome and a condition of action [14, $16,18]$.

3. Transparency: "Infrastructure is transparent to use in the sense that it does not have to be reinvented each time or assembled for each task, but invisibly supports those tasks" [16].

4. Large reach or scope: Infrastructure is ubiquitous, widely accessible, and supports many users $[14,16,19,20]$.

5. Taken-for-grantedness: Infrastructure is taken for granted in the sense that outsiders view infrastructure as an object that they need to learn about to become a member of a community of practice $[16,19]$.
6. Interoperability: Infrastructure is interoperable as it leverages standards and thus takes an invisible stance $[16,19]$.

7. Visibility upon breakdown: Infrastructure is usually invisible. When it breaks down, it becomes a visible object $[16,19]$.

8. Installed base inertia: Infrastructure does not grow de novo; its evolution is both enabled and constrained by the installed base (its current configuration of components) $[14,16]$.

9. Resolution of local and global tension: "An infrastructure occurs when the tension between local and global is resolved. That is, an infrastructure occurs when local practices are afforded by a larger-scale technology, which can then be used in a natural, ready-to-hand fashion" [16].

10. Distributed control: Control over infrastructure is distributed and dynamically negotiated [14, 19].

11. Regulated in public interest: Infrastructure is "administratively regulated in public interest; sometimes private or public monopoly" [19].

\subsection{Properties of Digital Platforms}

Moving from infrastructural properties to platform properties, we argue that digital platforms operate on top of digital infrastructures and define them as "a set of digital resources - including services and content - that enable value-creating interactions between external producers and consumers" [13]. Further, we argue that, identical to infrastructure, digital platforms need to be viewed from a relational perspective. Things emerge to be digital platforms and are not a priori digital platforms. For instance, Apple's mobile operating system is not a digital platform per se, but it has become one by opening up to external producers [21].

Recent literature has further specified the concept of digital platforms due to different economic and strategic logics. For example, Cennamo [22] distinguished three types of digital platforms: (1) multisided transaction, (2) complementary innovation, and (3) information platforms. Multisided transaction platforms refer to digital platforms that connect transactions across different market sides (e.g., Amazon Marketplace). Meanwhile, complementary innovation platforms relate to digital platforms facilitating complementary innovation and offering integrated solutions to consumers (e.g., Google Android). Lastly, information platforms refer to digital platforms that simplify information search and exchanges (e.g., Facebook). 
Although different types of digital platforms exist [23], they largely emerged to share the following properties:

1. Third-party development and orchestration: Platforms are open to external producers and orchestrate producers' complements to enhance the platform's functionality and capability [24].

2. Connection of heterogeneous user groups: Platforms facilitate interactions between distinct groups that would otherwise have difficulty finding each other [14, 25].

3. Modularity: Platforms are modular in the sense that they use boundary resources between platform core and complementary components [26].

4. Affordances and constraints: Platforms provide boundary resources such as software development kits to increase its digital affordances, where affordances represent opportunities for complementors to co-create value-adding complements [27]. Platforms simultaneously constrain complementors and channel them toward the interests of the platform owner [19].

5. Network effects. Platform users gain value by other users joining the platform [22, 23]. Network effects can manifest within one side of the platform (e.g., the more consumers join an ecommerce platform the more reviews available) and across platform sides (e.g., the more developers join a mobile platform the more apps are available to consumers).

6. Generativity: Platforms leverage ecosystems' generativity so that complementors can actualize digital affordances to develop unforeseeable functionalities beyond the platform owners' capabilities [28].

7. Centralized control: Control over the platforms is centralized, and rules are unilaterally imposed by the platform owner.

8. Regulated through competition: Platforms are regulated by common legal frameworks, such as antitrust and intellectual property; they do not serve the public interest [19].

To summarize, infrastructures, especially digital infrastructures, and digital platforms are not perfectly distinguishable; they have some overlapping characteristics. Hence, some authors argue that digital platforms are a less complex subtype of digital infrastructure with more centralized control mechanisms [14, 29]. However, infrastructures and digital platforms differ in scale and scope [19]. Infrastructures integrate various social and technical components on a large scale through interoperability and decentralized control. Most infrastructures are widely accessible, taken for granted, and transparent in use. In addition, governments strictly regulate some infrastructures. Digital platforms are generally of smaller scales and scopes. Platform owners leverage a modular design through which they enjoy a plethora of third-party components without forfeiting control over the platform. Digital platforms serve the interest of the platform owner and not public interests, and are not specifically regulated by governments.

\subsection{Essentiality}

The concept of essentiality has its roots in the essential facility doctrine, which relates to the framework of refusal to deal and requires monopolists to share facilities essential to competition with rivals $[30,31]$. Therefore, essentiality refers to a facility or input that is indispensable for competition.

The economic concept indicates that essentiality is relational. That is, nothing is per se essential; something (facility or input) is perceived as essential by someone (rivals) for the purpose of something (competition). This corresponds to prior work on essential data by Colangelo and Maggiolino [30] who also added another critical aspect: "a resource is not essential as such; it is essential in relation to 'something' and in comparison with the other inputs that can be used in relation to that 'something' " (italic added by the authors). Hence, an essential resource also needs to be viewed in relation to an alternative resource. For example, some consumers will probably perceive a car as more essential than a bicycle compared to a scooter when their goal is to get to a distant place. This means that an essential resource should be compared to a viable alternative instead of any alternative to derive meaningful insights of whether the resource is indeed perceived as essential. We argue that an "alternative" represents any given choice or possible solution for a specific need, whereas a "viable alternative" represents a feasible or realistic choice or solution for that need. If someone believes that no viable alternative exists compared to the resource of interest, we argue that the resource is perceived as essential. However, this does not demonstrate that the resource is objectively essential or that others share this perspective. The idea of a viable alternative strongly matters on what someone believes is a viable alternative. We argue that "viable" in the context of digital platforms is a matter of substitutability, switching costs, and multihoming costs.

Substitutes are defined as interrelated goods in the sense that an increase in the price of a good will increase demands for its substitutes. More generally, 
substitutes represent goods that can replace each other in use (or consumption) as they satisfy the same needs and correspond in various characteristics such as price, quality, performance, and effort to use. Switching costs are defined as the costs that consumers face to change between substitute products [32, 33]. Switching costs result, for instance, from network effects, learning, and data portability. Lastly, multihoming costs describe the sum of costs that users must invest for their participation in more than one platform (e.g., operation and opportunity costs) [34].

We propose that a viable alternative represents a substitute to the resource of interest and requires low switching or multihoming costs. For instance, an Uber rider probably perceives Lyft as a viable alternative because Lyft satisfies the same need (on-demand mobility), corresponds in various characteristics (e.g., price), and requires low switching costs (e.g., low learning costs and sufficient drivers available) or multihoming costs (e.g., similar operational costs as single homing). In contrast, users of messaging applications (e.g., WhatsApp) might argue that alternatives such as Telegram or Signal do not represent viable alternatives. Although these alternatives satisfy the same need (messaging), correspond in various characteristics (e.g., functionality), and require low multihoming costs (e.g., low costs of maintaining two profiles), they require high switching costs (e.g., loss of personal network). Hence, Uber riders might argue that Uber is not essential, whereas WhatsApp might be generally perceived as essential by its users.

To summarize, we view essentiality as a relational concept defined as the perception of someone that no viable alternative exists to the resource of interest to reach a specific objective.

\subsection{Abuse of Power and Regulation}

The concept of abuse of power is rooted in competition law and used by Article 102 of the Treaty on the Functioning of the European Union as follows: "Any abuse by one or more undertakings of a dominant position within the internal market or in a substantial part of it shall be prohibited as incompatible with the internal market in so far as it may affect trade between Member States." Abusive behavior includes practices such as predatory pricing, exclusive dealing, refusal to supply, and tying. Although this narrow concept of abuse of power is well suited for competition analysis, we take a broader perspective to account for other public interests such as consumer interests (e.g., privacy law), freedom from improper influence (e.g., labor law), as well as integrity and continuity (e.g., of platforms that are used by other platforms) (see Nooren, et al. [35] for a discussion of the four types of public interests in the platform economy). Hence, our understanding of abuse of power is not restricted to the abuse of market power that results from a dominant position. We view power more generally in the sense that "power has to do with relationships between two or more actors in which the behavior of one is affected by the behavior of the other" (Hall 1999, p. 110, as cited in Jasperson, et al. [36]). This conceptualization of power allows us to acknowledge abuse of power outside of competition law and to recognize its occurrence in other legal domains.

Having conceptualized abuse of power outside of competition law suits the concept of regulation. That is because in the European Union competition enforcement and regulation differ in their rationale and approach. While competition enforcement punishes anti-competitive behavior ex-post, regulation prevents abusive behavior ex-ante whereby it is not limited to competition objectives. Regulation can promote various (possibly contradicting) objectives such as effective competition, users' interests, and environmental standards. Moreover, regulation applies common rules to specific issues whereas competition enforcement is concerned with case-bycase analyses. Regulation is usually sector-specific although sometimes it can apply to multiple sectors. In contrast, competition enforcement is per se horizontal and cross-sectoral [37].

\section{Table 1: Summary of key terms}

\begin{tabular}{|c|c|c|}
\hline Term & Definition & Examples \\
\hline $\begin{array}{l}\text { Digital } \\
\text { Platform }\end{array}$ & $\begin{array}{l}\text { "[...] a set of digital } \\
\text { resources-including } \\
\text { services and content-that } \\
\text { enable value-creating } \\
\text { interactions between } \\
\text { external producers and } \\
\text { consumers" [12]. }\end{array}$ & $\begin{array}{l}\text { Apple iOS, } \\
\text { Google Search, } \\
\text { and Airbnb. }\end{array}$ \\
\hline $\begin{array}{l}\text { Digital } \\
\text { Infrastructure }\end{array}$ & $\begin{array}{l}\text { "[...] the computing and } \\
\text { network resources that allow } \\
\text { multiple stakeholders to } \\
\text { orchestrate their service and } \\
\text { content needs" [13]. }\end{array}$ & $\begin{array}{l}\text { Internet, data } \\
\text { centers, and open } \\
\text { standards (e.g., } \\
\text { USB and TCP) }\end{array}$ \\
\hline $\begin{array}{l}\text { Viable } \\
\text { Alternative }\end{array}$ & $\begin{array}{l}\text { A substitute to the resource } \\
\text { of interest that requires low } \\
\text { switching or multihoming } \\
\text { costs. }\end{array}$ & \multirow{2}{*}{$\begin{array}{l}\text { For a map-based } \\
\text { app a developer } \\
\text { perceives Google } \\
\text { Maps as more } \\
\text { essential than a } \\
\text { self-developed } \\
\text { mapping service } \\
\text { compared to } \\
\text { HERE Maps. }\end{array}$} \\
\hline Essentiality & $\begin{array}{l}\text { The perception of someone } \\
\text { that no viable alternative } \\
\text { exists to the resource of } \\
\text { interest to reach a specific } \\
\text { objective. }\end{array}$ & \\
\hline $\begin{array}{l}\text { Abuse of } \\
\text { Power }\end{array}$ & $\begin{array}{l}\text { The act of one actor using its } \\
\text { power to negatively } \\
\text { influence another actor. }\end{array}$ & $\begin{array}{l}\text { Uber classifying } \\
\text { drivers as } \\
\text { contractors instead } \\
\text { of employees. }\end{array}$ \\
\hline
\end{tabular}




\begin{tabular}{|l|l|l|}
\hline Regulation & $\begin{array}{l}\text { "Regulation 'limits' or } \\
\text { corrects markets with } \\
\text { interventions to achieve a set } \\
\text { policy goal" [37]. }\end{array}$ & $\begin{array}{l}\text { Prohibiting the use } \\
\text { of own in-app } \\
\text { purchase system. }\end{array}$ \\
\hline
\end{tabular}

\section{Toward a Framework of Essential Platform Infrastructure}

Having outlined the theoretical foundations of infrastructures, digital platforms, and essentiality, we theorize their intersections intending to build a Venn diagram for essential platform infrastructure.

\subsection{Infrastructuralized Platforms}

The idea that infrastructures and digital platforms overlap is particularly evident when looking at large platform operators such as Google or Apple. Some of the platforms that these companies operate indeed indicate both infrastructure and platform properties (e.g., iOS and Android). However, not all platforms have infrastructural properties. Most industrial internet of things platforms, for example, serve a narrow use case (small scope) and are used by small numbers of users (small scale). To reflect the process of platforms obtaining infrastructural properties, we follow Plantin, et al. [19], Helmond, et al. [38], and de Reuver, et al. [29] and term these platforms infrastructuralized platforms. Such platforms are for instance the WeChat platform [20], the Facebook platform [19, 29, 38], and the Google Maps platform [39].

All three have grown into a ubiquitous state, became widely accessible, accumulated huge user numbers, and developed into foundations of multiple use cases. The three platforms also became widely embedded in other systems and applications. For example, online shopping platforms use Facebook's marketing API and authentication API, mobility service providers use the Google Maps API, and financial transactions are often conducted via WeChat in China. Furthermore, the platforms evolved into being taken for granted by consumers and developers in the sense that they view these platforms as an object they need to learn about to engage in their community of practice. The three platforms are also transparent to use as they invisibly support various tasks (which is even more prevalent for consumers than developers) without the need to be reinvented each time and would become visible upon breakdown.

\subsection{Platform Essentiality}

Platform essentiality draws on the relational concept of essentiality and is concerned with the essentiality of one specific platform (e.g., iOS or Android) as perceived by its users. For instance, by consumers, app developers, and device manufacturers in the case of a mobile platform. Hence, this perspective assumes that essentiality is dynamic and relational, and that it can only be assessed through subjective measures and an interpretivist stance. A platform is not per se essential; it becomes essential when someone perceives that no viable alternative exists to reach a specific objective. This implies that a platform can be perceived as essential for multiple objectives and that those objectives differ within and especially across user sides.

For example, Facebook's essentiality can be assessed by consumers and businesses. Both have different objectives with Facebook: consumers aim to interact with friends, whereas businesses aim to interact with customers and advertise their products. Consequently, consumers might argue that other social media platforms that support the objective of interacting with friends do not represent a viable alternative because they are not a good substitute for that objective or exhibit high switching and multihoming costs. Consumers might argue that alternative platforms do not offer the same variety of features (messaging, posting, video calling, gaming, and live streaming), do not cover as many friends as Facebook, and profiles as well as posts are costly to keep up to date on both platforms. Hence, although other social media platforms represent alternatives, they might not represent viable alternatives due to their lack of offering a holistic interaction experience (substitutability), connecting the same number of friends (switching costs), or reducing recurring tasks (multihoming costs), indicating that Facebook has become essential to interact with friends.

However, when taking the business perspective, businesses might compare Facebook to two different types of alternatives: alternatives that support customer interaction (e.g., email, a chatbot on the website, or other social media platforms) and alternative advertisement platforms (e.g., Google Ads, Amazon Ads, or LinkedIn Ads). Businesses might argue that alternative services for customer interaction represent viable alternatives because alternatives offer similar functionalities, similar access to customers, and require low switching or multihoming costs. This indicates that Facebook has not become essential for businesses to interact with customers. Regarding advertisement, businesses might argue that alternative advertisement platforms do not leverage similar social information (e.g., political opinion, cultural background, or emotional state) about their users to offer a substitutable quality in personalized advertisement to Facebook. This indicates that 
Facebook has become essential for advertising goods even though switching and multihoming costs might be low.

Furthermore, even platforms of the same service domain are not equally essential just because they operate in the same domain. For example, both Apple's and Google's mobile app platforms reside in the operating system (iOS and Android) and app distribution (App Store and Play Store) domain. In general, app developers might perceive both platforms as equally essential for running and distributing their app since consumers usually single home. Hence, if app developers want to reach out to all consumers it is essential for them to offer their app on both platforms. However, if an app specifically serves the needs of emerging markets (e.g., mobility app in India), app developers would probably support our claim that Google's platform will be more essential than Apple's platform. This is because iOS is largely associated with consumers stemming from developed countries having higher income and higher education, whereas Android is also prevalent in developing countries. Hence, Android is more essential than iOS if the objective of the app developer is to distribute the app in emerging markets. Both the general and the specific scenario illustrate our argument that platforms in the same domain are perceived as differently essential depending on the user itself, the purpose for which the platform is used, and the alternatives to which the platform is compared.

\subsection{Essential Platform Infrastructure}

Essential platform infrastructures represent platforms that have obtained infrastructural properties and are perceived by their users as essential. In general, this type refers to digital platforms that are large in scale and scope, and perceived to compete against no viable alternative. For example, the Android platform is embedded into different smartphones, reaches billions of users, is taken for granted, supports various use cases, and is perceived as essential compared to the iOS platform by app developers to reach users in emerging markets. We propose to differentiate essential platform infrastructures from basic platforms, essential platforms, and infrastructuralized platforms. Figure 1 shows the four types of digital platforms resulting from a Venn diagram on essentiality, platform properties, and infrastructural properties.

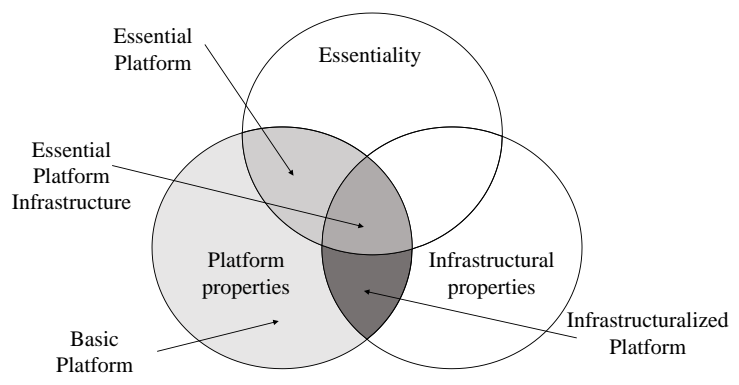

Figure 1: Four types of digital platforms

Basic platforms are digital platforms that are neither perceived as essential by their users nor have they obtained infrastructural properties. In general, this type refers to platforms that are small in scale and scope, and perceived to compete against viable alternatives.

Essential platforms are digital platforms that are perceived as essential by their users but who have not obtained infrastructural properties. In general, this type refers to platforms that are small in scale and scope, and perceived to compete against no viable alternative. For example, industrial internet of things platforms are used by a small number of users, support specific use cases, and likely to be perceived as essential by its users for that use case.

Lastly, infrastructuralized platforms are digital platforms that are not perceived as essential by their users, but have obtained infrastructural properties. In general, this type refers to platforms that are large in scale and scope, and perceived to compete against viable alternatives. Cloud platforms, such as Dropbox, reach millions of users and are visible upon breakdown, but they are not essential to consumers because they can easily switch to a viable alternative.

\section{Essential Platform Infrastructure and the Need for Regulation}

To address abuse of power in the platform economy, researchers and regulators emphasize the necessity of platform regulation. A recurring challenge within that debate is the definition of which platforms should fall under regulation and which should not. We argue that platform essentiality and infrastructural properties are two suitable concepts to derive the need for regulation. Platform essentiality, defined as the perception that no viable alternatives exist compared to the platform of interest to reach a specific objective, functions as an indicator of platform power - the ability to act independently from competitors, complementors, and consumer preferences. Platform power gives organizations the ability to engage in unilateral abusive behavior. An organization with total 
platform power can therefore abuse power without losing customers or complementors to competitors. According to our definition, we argue that total platform power represents the case in which all users perceive a platform as essential for all objectives. This means that the more essential a platform becomes; the less viable alternatives exist for users to switch to. As a result, the platform can act more independently and can more easily abuse its power because users are unwilling or even unable to abandon the platform.

In contrast, infrastructural properties indicate the number of entities and sectors affected by a potential abuse of power. By entities we understand both human users and technical systems, and by sector we understand different service types, markets, industries, or more generally use cases. As a platform develops infrastructural properties, it increases its scale and scope and becomes taken for granted and widely accessible by various entities. On one extreme, the platform becomes a de-facto standard for multiple user groups and use cases. It has sunk into the background and turned invisible to the community of practice. Moreover, the platform achieved to afford local practices by a larger-scale technology and therefore became a complete infrastructure. On the other end of the spectrum, the platform supports a small number of users and use cases. Thus, it has not become ubiquitous, is largely visible before breakdown, and only embedded to a small extent. This type of platform cannot be considered an infrastructure because it has not obtained infrastructural properties. Hence, the more a platform develops infrastructural properties, the more it can be considered a complete infrastructure and thereby the larger its potential damage in case of abuse of power. Both dimensions, that is, platform power as well as number of entities and sectors affected, indicate the magnitude of potential damage. The higher the magnitude of the potential damage, the higher the need for regulation (Figure 2).

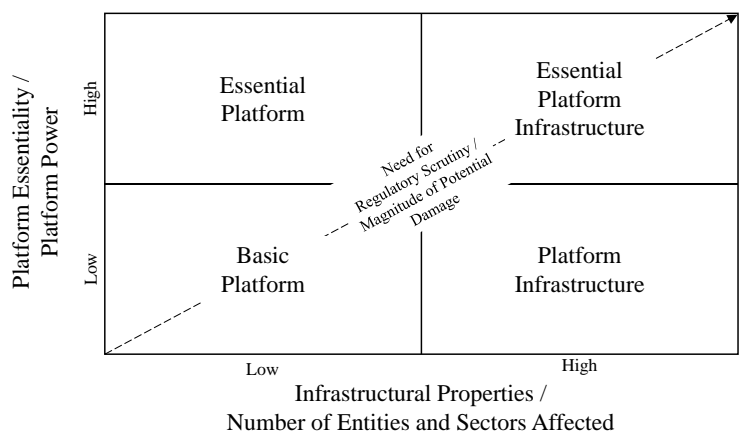

Figure 2: Essential platform infrastructure and the need for regulation
It should be noted that "platform power" and "number of entities and sectors affected" are part of a larger model to assess the need for regulation. We argue that the need for regulation is the product of the likelihood of abuse and the severity of abuse.

The likelihood of abuse is determined by platform power and the willingness to abuse power. Just holding significant power and thereby being able to abuse power does not implicate that power will be actually abused. However, willingness to abuse power is difficult to measure. It might be approximated by looking at past behavior in the sense that an organization that has already abused its power in the past might be more willing to abuse its power in the future. Although this approach might yield reasonable predictions for platform organizations with records of past behavior, it is not applicable to new platform organizations and does not account for behavioral change. For those reasons, willingness to abuse power is excluded from the proposed model to assess the need for regulation.

For the severity of abuse, we argue that it is determined by the intensity of abuse and the number of entities and sectors affected. The intensity of abuse thereby represents how strongly a platform is abusing its power. We would argue that, for example, biasing recommendations toward own downstream services is less intense than biasing recommendations and demoting rival services. However, the intensity of abuse can only be determined ex-post. Consequently, the concept is not suitable for the objective of establishing or even predicting the importance of a new platform of investigation a priori.

\section{Theoretical and Practical Implications}

The proposed concept of essential platform infrastructure makes three contributions to theory. First, it contributes to the debate of differentiating digital platforms and digital infrastructures. Some authors argue that digital platforms operate on top of digital infrastructures [13], while others argue that digital platforms are a less complex subtype of digital infrastructures with more centralized control mechanisms [14, 29]. Essential platform infrastructure bridges both perspectives by taking a relational perspective and drawing on the work that digital platforms and digital infrastructures emerge along certain properties [16, 19]. As a result, digital platforms and digital infrastructures can sometimes refer to the same artefact. However, they can also exhibit more or less properties of one another or they can be completely distinct. Allowing the free combination of properties thereby resolves the issue of trying to perfectly distinguish digital platforms from 
digital infrastructure and acknowledges that certain mixtures of both exist as well.

Second, the concept of essential platform infrastructure contributes to the refinement of the concept of essentiality. While prior work emphasized that it is critical to assess a resource in comparison to something to derive its essentiality $[30,31]$, it does not provide clear guidance to what exactly the resource should be compared. We propose to compare the resource of interest to a viable alternative instead of just any alternative to derive meaningful insights of whether the resource is indeed perceived as essential. We argue that a viable alternative represents a substitute to the resource of interest and requires low switching or multihoming costs.

Third, essential platform infrastructure also contributes to the contextualization of essentiality to the domain of digital platforms. We propose that platform essentiality describes that platforms are not per se essential; they become essential when someone perceives that no viable alternative exists to reach a specific objective with that platform. Consequently, platform essentiality represents a new construct for the platform literature and can help explain user behavior on platforms. For instance, platform essentiality may predict developer contribution behavior such as developing a new app, updating an existing app, willingness to advocate the platform, or willingness to switch.

The proposed framework of essential platform infrastructure and the need for regulation contributes to regulatory practice. The framework supports regulators in identifying which platforms exhibit a significant magnitude of potential damage in case of abuse of power and therefore should fall under regulation. As a next step, regulators can assess which obligations and prohibitions are suitable to support which policy goal and whether these regulations should apply horizontally or sector-specific.

\section{Avenues for Future Research}

Our concept of essential platform infrastructure offers a complementary approach to address the challenge of defining digital platforms worthy of regulation. However, the proposed concept is limited by its theoretical and abstract nature and thus gives rise to various avenues for future research.

First, we encourage future research to refine the concept of platform essentiality and develop appropriate constructs. Although this paper puts forward a high-level definition of platform essentiality, future research needs to identify the underlying dimensions based on which a platform's degree of essentiality should be assessed. Hence, empirical work is needed to understand which objectives are pursued with a platform by which type of users and which aspects among those objectives matter for essentiality. For instance, app developers might find software platforms, such as Android or iOS, relevant for three objectives: creating, distributing, and monetizing their app. For each objective, future research can investigate which underlying aspects matter for essentiality. For instance, for value creation, the essential aspects could be development tools or APIs, whereas for value capture, this might be the app marketplace and the billing system. For each aspect, future research can further derive the criteria based on which the platform of interest should be compared vis-à-vis potential viable alternatives. For example, to assess the essentiality of a platform's APIs, developers could be asked to indicate the availability, functionality, or integration effort compared to APIs of alternative platforms. Such granular contextualization will contribute more nuanced knowledge to the concept of platform essentiality. However, operationalizing platform essentiality for each digital platform is challenging and not optimal for regulators with limited resources. Hence, future research can examine whether certain objectives and aspects of platform essentiality remain constant across platform types such as innovation and transaction platforms [40]. For instance, mobile app platforms and internet of things platforms might both reveal that developers aim to pursue value creation, distribution, and capture with these platforms.

Second, future research is encouraged to explore the thresholds for when a platform should be considered essential and how different thresholds inform regulatory practice. For instance, is a platform essential once the majority of one user side indicates that the platform has become essential to them, should both sides indicate platform essentiality, or might it be sufficient if a certain percentage of users indicate platform essentiality? Depending on which thresholds, or combinations of thresholds, are used, future research needs to reveal how this impacts regulatory practice. For example, if one user side is sufficient to indicate platform essentiality, this can largely reduce regulatory effort. However, this also bears the risk that regulations are set in place which favor one user side over the other side(s) of the platform.

Third, taking a more high-level and less usercentric perspective into account, future research can employ the framework of essential platform infrastructure and the need for regulation (Figure 2) to conduct classification workshops with regulators. During these workshops, regulators could classify platforms into the four types of basic platforms, 
essential platforms, infrastructuralized platforms, and essential platform infrastructures. This approach will help future research to identify essential platform infrastructures and to reveal the differentiating factors between each platform type. Compared to the approach in which users indicate the degree of essentiality of each platform, this high-level, regulator-centric approach can lead to quicker but probably less informed results.

Fourth, building on the regulator-centric approach, future research might engage in design science research to turn the proposed framework (Figure 2) from a simple 2-by-2 matrix into an interactive IT artifact with metrics, benchmarks, and visualizations. It could provide an engaging and easyto-use tool that presents regulators with a real-time topology of the digital platform landscape with recommendations on which platforms might develop into essential platform infrastructures in the near future.

Fifth, after having identified essential platform infrastructures, future research is encouraged to assess which kind of regulations should be adopted and whether they should apply horizontally or sectorspecific. It will be critical to discuss which policy goal to prioritize and to determine the extent of regulatory intervention (e.g., transparency and reporting obligations versus structural remedies).

Lastly, we encourage future research to engage with the central theme of how the EU can catch up in global tech leadership to sustain its digital sovereignty [e.g., 41, 42]. While the proposed framework guides EU regulators to make efficient use of their resources to scrutinize relevant platforms, this only represents one side of catching up in tech leadership. The other side covers the option of helping EU regulators and policy-makers to foster the development of essential platform infrastructures made in the EU. To this end, future research can explore the optimal degree of regulation and self-developed essential platform infrastructures as well as the overarching questions of whether and especially how the EU can build its own viable alternatives.

\section{Conclusion}

The regulation of digital platforms has recently received increased attention from research and practice. This is because large platform providers, such as Google, Apple, and Facebook, are more and more abusing their power [3-7]. To address abuse of power, current debates discuss the application of regulations that should impose certain obligations or prohibitions on specific platforms and regulate their behavior a priori [11]. A recurring challenge within that debate is the definition of which platforms should fall under regulation and which should not. To this end, we propose the concept of essential platform infrastructure which represents digital platforms that have obtained infrastructural properties (e.g., large reach, large scope, and taken for granted) and are perceived by its users as essential. Essentiality thereby refers to the perception of users that no viable alternative exists to the platform of interest to reach a specific objective. Once a digital platform has achieved this status, we argue that it should fall under regulation because it has obtained significant power and affects a variety of entities and sectors. As a result, such a platform exhibits a significant magnitude of potential damage compared to less powerful and smaller digital platforms. Our framework contributes to regulatory practice by helping regulators to cope with their limited resources by focusing on digital platforms that matter. It also contributes to research on platform regulation.

\section{Acknowledgements}

This work was in part funded by the Deutsche Forschungsgemeinschaft (DFG, German Research Foundation) - project no. 444990299.

\section{References}

[1] Evans, P.C. and A. Gawer, The rise of the platform enterprise: a global survey. 2016.

[2] Khan, L., Amazon's antitrust paradox. Yale LJ, 2016. 126(3): p. 710-805.

[3] Srinivasan, D., Why Google Dominates Advertising Markets Competition Policy Should Lean on the Principles of Financial Market Regulation. Stanford Technology Law Review, 2020. 24(1): p. 55-175.

[4] Srinivasan, D., The Antitrust Case Against Facebook: A Monopolist's Journey Towards Pervasive Surveillance in Spite of Consumers' Preference for Privacy. Berkeley Business Law Journal, 2019. 16(1): p. 39-101.

[5] Edelman, B.G. and D. Geradin, Efficiencies and regulatory shortcuts: How should we regulate companies like Airbnb and Uber. Stan. Tech. L. Rev., 2016. 19(2): p. 293-326.

[6] Edelman, B., Does Google leverage market power through tying and bundling? Journal of Competition Law \& Economics, 2015. 11(2): p. 365-400.

[7] Clemons, E., et al. Computing and Social Welfare: Minimizing the Societal Harm from Digital Transformation While Preserving the Benefits of Innovation. in Proceedings of the 54th Hawaii International Conference on System Sciences. 2021. Kauai, Hawaii, USA.

[8] European Commission. Antitrust: Commission fines Google $€ 2.42$ billion for abusing dominance as search engine by giving illegal advantage to own comparison 
shopping service. 2017 [cited 2019 01.05.]; Available from: http://europa.eu/rapid/press-release_IP-17-1784_en.htm. [9] European Commission. Antitrust: Commission fines Google $€ 4.34$ billion for illegal practices regarding Android mobile devices to strengthen dominance of Google's search engine. 2018 [cited 2019 01.05.]; Available from: http://europa.eu/rapid/press-release_IP-18-4581_en.htm.

[10] Stigler Committee on Digital Platforms. Final Report. 2019 [cited 2021 16.04.]; Available from: https://research.chicagobooth.edu/stigler/media/news/com mittee-on-digital-platforms-final-report.

[11] European Commission. Regulation of the European Parliament and of the Council on contestable and fair markets in the digital sector (Digital Markets Act). 2020 [cited 2021 13.04.]; Available from: https://eurlex.europa.eu/legalcontent/en/TXT/?uri=COM\%3A2020\%3A842\%3AFIN. [12] Easley, R.F., H. Guo, and J. Krämer, Research commentary-From net neutrality to data neutrality: A techno-economic framework and research agenda. Information Systems Research, 2018. 29(2): p. 253-272.

[13] Constantinides, P., O. Henfridsson, and G.G. Parker, Introduction-Platforms and Infrastructures in the Digital Age. Information Systems Research, 2018. 29(2): p. 381400.

[14] Hanseth, O. and K. Lyytinen, Design theory for dynamic complexity in information infrastructures: the case of building internet, in Enacting Research Methods in Information Systems. 2010, Springer. p. 104-142.

[15] Tilson, D., K. Lyytinen, and C. Sørensen, Research commentary-Digital infrastructures: The missing IS research agenda. Information systems research, 2010. 21(4): p. 748-759.

[16] Star, S.L. and K. Ruhleder, Steps toward an ecology of infrastructure: Design and access for large information spaces. Information systems research, 1996. 7(1): p. 111134.

[17] Engeström, Y., When is a tool? Multiple meanings of artifacts in human activity, in Learning, working and imagining: Twelve studies in activity theory. 1990, Orientakonsultit.

[18] Bygstad, B., Generative innovation: a comparison of lightweight and heavyweight IT. Journal of Information Technology, 2017. 32(2): p. 180-193.

[19] Plantin, J.-C., et al., Infrastructure studies meet platform studies in the age of Google and Facebook. New Media \& Society, 2018. 20(1): p. 293-310.

[20] Plantin, J.-C. and G. de Seta, WeChat as infrastructure: the techno-nationalist shaping of Chinese digital platforms. Chinese Journal of Communication, 2019. 12(3): p. 257273.

[21] Eaton, B., et al., Distributed tuning of boundary resources: the case of Apple's iOS service system. MIS Quarterly, 2015. 39(1): p. 217-243.

[22] Cennamo, C., Competing in Digital Markets: A Platform-Based Perspective. Academy of Management Perspectives, 2019(In Press).

[23] Hein, A., et al., Digital platform ecosystems. Electronic Markets, 2020. 30(1): p. 87-98.

[24] Tiwana, A., B. Konsynski, and A.A. Bush, Research commentary-Platform evolution: Coevolution of platform architecture, governance, and environmental dynamics. Information Systems Research, 2010. 21(4): p. 675-687.

[25] Evans, D.S. and R. Schmalensee, Catalyst code: the strategies behind the world's most dynamic companies. 2007: Harvard Business School Press.

[26] Baldwin, C.Y. and C.J. Woodard, The architecture of platforms: A unified view, in Platforms, markets and innovation. 2008, Cheltenham: Edward Elgar Publishing. p. $19-44$.

[27] Nambisan, S., M. Wright, and M. Feldman, The digital transformation of innovation and entrepreneurship: Progress, challenges and key themes. Research Policy, 2019. 48(8): p. 103773.

[28] Zittrain, J.L., The generative internet. Harvard Law Review, 2006: p. 1974-2040.

[29] de Reuver, M., C. Sørensen, and R.C. Basole, The digital platform: a research agenda. Journal of Information Technology, 2017. 33(2): p. 124-135.

[30] Colangelo, G. and M. Maggiolino, Big data as misleading facilities. European Competition Journal, 2017. 13(2-3): p. 249-281.

[31] Abrahamson, Z., Essential data. Yale LJ, 2014. 124(4): p. 867-881.

[32] Ray, S., S.S. Kim, and J.G. Morris, Research noteOnline Users' switching costs: Their nature and formation. Information Systems Research, 2012. 23(1): p. 197-213.

[33] Parker, G., et al., Platform revolution: How networked markets are transforming the economy and how to make them work for you. 2016, New York, USA; London, UK: W.W. Norton \& Company.

[34] Kapoor, K., et al., A socio-technical view of platform ecosystems: Systematic review and research agenda. Journal of Business Research, 2021. 128: p. 94-108.

[35] Nooren, P., et al., Should we regulate digital platforms? A new framework for Evaluating policy options. Policy \& Internet, 2018. 10(3): p. 264-301.

[36] Jasperson, J.S., et al., Power and information technology research: A metatriangulation review. MIS Quarterly, 2002. 26(4): p. 397-459.

[37] EU, Competition Enforcement and Regulatory Alternatives - Note by the European Union, in Working Party No. 2 on Competition and Regulation (OECD). 2021. [38] Helmond, A., D.B. Nieborg, and F.N. van der Vlist, Facebook's evolution: development of a platform-asinfrastructure. Internet Histories, 2019. 3(2): p. 123-146.

[39] Plantin, J.-C. and A. Punathambekar, Digital media infrastructures: pipes, platforms, and politics. Media, Culture \& Society, 2019. 41(2): p. 163-174.

[40] Gawer, A., Digital platforms' boundaries: The interplay of firm scope, platform sides, and digital interfaces. Long Range Planning, 2020. In Press.

[41] Hermes, S., et al. Breeding Grounds of Digital Platforms: Exploring the Sources of American Platform Domination, China's Platform Self-Sufficiency, and Europe's Platform Gap. in 28th European Conference on Information Systems. 2020. Marrakesh, Morocco.

[42] Hermes, S., et al. Gaining Control over Critical Platforms: A Comparative Case Study of European Consortia in 28th European Conference on Information Systems. 2020. Marrakesh, Morocco. 